\title{
The Lineage of Mindfulness
}

\author{
Edo Shonin • William Van Gordon
}

Published online: 5 August 2014

(C) Springer Science+Business Media New York 2014

Whenever we are travelling or teaching in the West and we meet new people, they invariably initially respond in one of three ways. The first way is to immediately state or exclaim that 'you are monks'. We haven't quite worked out yet whether this is supposed to be a manner of greeting, an expression of shock or just a statement of fact. The second response- which also happens to be the one we prefer most - is for people to either shake our hands or to put their palms together before all parties gently bow. The third response that we frequently encounterwhich brings us onto the subject of this article - is for people to forgo even saying hello and to straightaway ask the question 'What lineage are you?' We don't encounter people asking this question quite so much when we are in the East, but in the West, people seem to place a great deal of importance on establishing which particular lineage a person 'belongs' to. It is not just between Buddhist meditation practitioners where lineage seems to be a frequent topic of discussion because we have also observed that the subject is increasingly being debated amongst individuals that follow secular approaches to meditation-including secular mindfulness-based approaches. In this Mindfulness in Practice article, following a brief explanation of the meaning of lineage, we introduce the concept of 'authentic spiritual transmission' and discuss the implications for Buddhist and non-Buddhist mindfulness practitioners wishing to advance along the path of awareness.

\section{Exactly what is Lineage?}

Lineage is basically about being able to trace the transmission-ancestry of a particular meditation tradition or

E. Shonin $(\bowtie) \cdot$ W. Van Gordon

Division of Psychology, Nottingham Trent University, Chaucer

Building, Burton Street, Nottingham NG1 4BU, UK

e-mail: meditation@ntu.ac.uk meditation teacher back to an individual that was seemingly endowed with at least a modest degree of authentic spiritual realization. In Buddhist settings, this individual is invariably the historical Buddha who lived approximately 2,500 years ago, but it can also be another enlightened being that expounded the teachings at a different point in time. In respect of secular meditation and mindfulness modalities, rather than an historic spiritual or religious figure per se, some mindfulness practitioners trace their lineage back to the founder of a particular mindfulness-based approach. Either way, lineage is essentially concerned with authenticity and preserving the spiritual potency or effectiveness of a particular line of teachings.

Thus, lineage effectively ensures the continuity of the true Dharma. This could be (for example) the Buddha-Dharma, Christ-Dharma, Guru Nanak-Dharma, Mohammed-Dharma, or depending upon a person's perspective and preferences, it could also be the spiritual-Dharma more generally. A common view held by many Buddhist and non-Buddhist meditation practitioners is that when looking for a suitable meditation teacher, one should ensure that they are of an established lineage. The general idea is that by working with or receiving teachings from a reputable 'lineage holder', a practitioner can reassure themselves that they are in good hands and are getting the 'real deal'.

Arguably, the method of lineage transmission that the majority of modern day meditation practitioners are most familiar with is that of oral transmission. Indeed, it seems that quite a number of meditation practitioners subscribe to the view that in order to consider themselves a lineage holder, they need to spend a certain amount of time receiving oral teachings directly from a lineage teacher. However, although oral transmission is probably the most obvious means by which lineage can be acquired, it is by no means the only one. For example, according to the twelfth century Tibetan Buddhist teacher, Gampopa, if the 'right student' at the 'right 
time' reads the 'right text' that was written by the 'right teacher', then this is the same as meeting the author of the text in person:

In the future, those who think, 'Alas, I haven't met him' [Gampopa], should simply study and practice the texts that I composed .... There is no particle of difference; it is the same as meeting me. Those who are having a hard time understanding and practising the Dharma, think of me and supplicate with devotion. The blessings will arise naturally.

This also seems to be the view of the nineteenth century Tibetan Buddhist teacher, Patrul Rinpoche:

In this world, such an eminent text [the Dharmadhatu Treasury by Longchenpa], is liberation through seeing, as well as hearing and recollecting. Whoever connects with it is a future Buddha. If you realise it, you are a Buddha of the present. As the power of the blessings lineage is unbroken, you will receive the wisdom of the true lineage through his trusted intention. Sealed with the entrustment to future disciples, it is equal to meeting the Omniscient master in person.

Based on the views of some Buddhist teachers, it seems that lineage can actually be directly transmitted via the written word. In addition to transmission by oral or written means, a further but perhaps less obvious form of lineage transmission that is referred to in the traditional meditation literature is that of mind-to-mind transmission. Transmissions of this nature are arguably less common than the abovementioned oral and written transmission formats, and mind-to-mind transmission requires a highly realised teacher and a student that is spiritually and karmically 'ripe'.

Interestingly, mind-to-mind transmissions do not actually require the teacher to be physically present. For example, the prominent eighth century Tibetan Buddhist teacher, Jigme Lingpa, is recorded as having received extensive volumes of teachings during visionary encounters with Manjushrimitra, Guru Rinpoche (also known as Padmasambhava), Vimalamitra and Longchenpa. Other reported examples include (i) the tenth century Buddhist saint, Tilopa, who received an entire lineage (the Dakini hearing lineage) during visionary encounters with Vajradakini; (ii) the Tibetan Buddhist teacher, Jamyang Khyentse Wangpo, who received extensive transmissions during visionary encounters with Zurchungpa and (iii) Garab Dorje, who received extensive essence transmissions directly from Buddha Vajrasattva.

Another form of lineage transmission that does not require a teacher to be physically present is that of 'terma' transmissions. Terma transmissions refer to spiritual practitioners finding - sometimes in their own minds - teachings that were hidden by previous enlightened teachers. Some reported examples of such individuals or 'treasure revealers' are the spiritual adepts Jatson Nyingpo, Rigdzin Godem and Jamyang Khyentse Wangpo. This is what the Buddhist teacher Tulku Urgyen Rinpoche said about terma transmissions and about lineage more generally:

As teachings are passed down from one generation to the next, it is possible that some contamination or damage of samaya may creep in. To counteract this, Padmasambhava in his immeasurably skilful wisdom and compassion gave us fresh hidden treasures [i.e., termas].... The distance from the Buddha to the practitioner is very short when a revelation is fresh and direct; there is no damage in the line of transmission. The purity or lack thereof lies not in the teaching itself, but in how distant the line of transmission is.

\section{Authentic Spiritual Transmission}

The purpose of the above section that briefly outlines some of the different means by which lineage may be transferred from one person to another, is to highlight a very important point regarding lineage and, hopefully, to dispel some common misconceptions. As we have already discussed, the whole idea of lineage is to ensure that the teachings and teacher are authentic and that they remain an effective means of bringing about spiritual growth in suitably disposed individuals. However, there are numerous ways in which a person can acquire a lineage. Some of these require a teacher to be physically present, but some don't. Some use methods that we are more accustomed to such as oral or written transmission, but others use methods that are not entirely explainable based on current scientific knowledge.

What this means in practice for the person wishing to advance along the path of mindfulness meditation, is that the only truly reliable means of assessing whether a potential teacher is a 'genuine lineage holder', is to determine whether they have given rise to authentic spiritual realization. The particular lineage that they claim to belong to and the manner in which the lineage was transmitted (e.g., orally, written, mind-to-mind, terma, etc.) is of relatively little consequence. Likewise, there is limited value in going to great efforts to establish how many titles or endorsements a particular teacher has, how many meditation books they have read, how many teachers they have trained with, or how many students practice with them. Put simply, if a teacher has genuine spiritual presence, this means that they are a lineage holder of the true Dharma. Being a Dharma lineage holder means that a person has realized and dwells within the truth of emptiness, 
unconditional compassion and steadfast awareness. As such, they are $100 \%$ authorized to transmit the Dharma teachings. In fact, the presence of inner spiritual realization is the only credential that counts. The following is a short contemplation that we wrote about authentic spiritual transmission:

If a person has genuine spiritual realization, they are authorized to transmit the spiritual teachings. All titles, held-lineages, endorsements, acclamations, life accomplishments, life mistakes, and years spent in training are irrelevant.

If a person is without genuine spiritual realization, they have no such authority. All titles, held-lineages, endorsements, acclamations, life accomplishments, life mistakes, and years spent in training are irrelevant.

Ultimately, true authorization to transmit the spiritual teachings comes from awaking to the timeless truth of emptiness. It seems that some form of spiritual guide is required to effectuate this awakening.

Please don't misunderstand what we are saying here. We are not saying that lineage is not important. Rather, what we are saying is that we need to take a step back and look at the underlying purpose of lineage. Belonging to a lineage theoretically ensures that a person has the necessary 'credentials' to be an effective meditation teacher, and as such, knowing an individual's lineage can help us make an informed decision about their suitability as a teacher. However, just because a given meditation or mindfulness teacher is from a scientific background and/or is not particularly interested in being part of a Buddhist lineage or tradition, this does not by default mean that they are not authentic. Likewise, just because a teacher belongs to an 'established' Buddhist or meditation lineage, this does not, by default, mean that they are able to impart an authentic transmission of the teachings.

Indeed, in these materialistic times, it is unfortunately sometimes the case that lineage can be used by a meditation teacher as a kind of marketing tool in order to attract a large following of people and/or financial support. There seems to be an increasing number of instances of meditation teachers (Buddhist and non-Buddhist) having all of the necessary education in scholarly and/or ceremonial matters, but without the more subtle spiritual presence that is the mark of a genuine realized being. This creates an unfortunate situation where all that is passed on from teacher to student is a dry semblance of the original teachings. In such cases and as time goes by, the lineage becomes increasingly corrupted, and maintaining and practicing the traditions of that lineage can even start to take precedence over maintaining and practising the Dharma. The
Buddha's close disciple, Ananda, talked about this problem in the Sandaka Sutta:

Again, Sandaka, here some teacher is a traditionalist, one who regards oral tradition as truth, he teaches a Dharma by oral tradition, by legends handed down, by the authority of the collections. But when a teacher is a traditionalist, one who regards oral tradition as truth, some is well transmitted and some badly transmitted, some is true and some is otherwise.

The crucial point is that lineage is a means of guiding people to enlightenment, but it is not enlightenment itself. It is a finger that points to the moon, but it is not the moon. A person only becomes a 'lineage holder' when they realize the inner meaning of the transmitted teachings and infuse them with all aspects of their being. How they came to this realization is of little consequence. Indeed, in the Canki Sutta, the Buddha explained that in terms of authenticity, the only thing that really matters is that a teacher's actions and behaviour are not in any way influenced by greed, hatred or delusion. The Buddha wasn't concerned with endorsements or lineages, he was only interested in whether a meditation teacher had tamed their mind. In fact, when the Buddha was asked about his own Dharma credentials, he gently touched the earth with the palm of his right hand. The Buddha did not descend from an established Buddhist lineage in the conventional sense and so by this action he was saying that the earth was his witness. The Buddha's own enlightened mind provided him with all of the credentials he needed.

Thus, when looking for a suitable mindfulness or Dharma teacher, as already indicated, we should try to avoid placing too much emphasis on superficial factors. We should definitely ask lots of questions and take time to get to know our prospective meditation teacher, but we should try to avoid having too many preconceived ideas. Likewise, we should also try not to be overly influenced by other people's opinions. To perform the role effectively, the meditation teacher must be highly skilled in understanding and guiding people's minds. According to the fifteenth century Buddhist saint, Tsong-khapa, they should be 'thoroughly pacified', 'serene' and 'disciplined'. Therefore, it is that air of uncontrived equanimity and boundless wisdom - the subtle mark of an enlightened being - that we are really interested in. Remember that realized spiritual guides can take various guises and may not always fit what we deem to be the 'perfect mould'. A good question to ask ourselves is: Do I feel nourished physically, mentally and spiritually when in this person's presence? Try to allow your intuitive mind to answer this question rather than being overly analytical. By taking this approach, if you are fortunate enough to cross paths with an authentic Dharma teacher, you will maximize your chances of recognizing them as such. 


\section{Finding the Lineage Within}

Earlier on in this article, we provided examples of the numerous and sometimes esoteric means by which a person can acquire a lineage and Dharma teachings. In addition to the methods already outlined, a further means of inheriting a spiritual lineage is transmission from the 'teacher within'. In the Kukkuravatika Sutta, the Buddha said 'Beings are the heirs of their actions'. This effectively means that we inherit the lineage of our own thoughts, words and actions. In other words, we are basically the founder and heir of our own lineage. Without exception, every sentient being is creating their lineage and they are also living it.

As mindfulness practitioners, we strive to practice full awareness of everything we think, say and do. Consequently, we are able to consciously mould and shape how our personal lineage develops. By infusing all of our actions with gentleness and awareness, the profundity of our spiritual realization steadily grows. Eventually, we become skilled at riding and dancing upon the wave-crest of the present moment, and we begin to see that every single experience and choice we make is a spiritual teaching. When we start to experience life as one big teaching, everything we encounter becomes an embodiment of the Buddha. We can start to meet the Buddha in every single breath and see his face in all that unfolds. In fact, all of the various types of lineage that we have referred to in this article are there to guide us towards the understanding that the most effective teacher-our indestructible enlightened essence-is already inside of us.

Although an awareness of the teacher within will gradually develop as we continue to practice mindfulness, there are certain things we can do in order to help this awareness to grow. In addition to being mindful of our breath, body, feelings and minds, we should also strive to be fully aware of our inherent potential for spiritual awakening. Practicing mindfulness with the full knowledge and understanding that enlightenment is a real possibility-including within this lifetime - adds an entirely new dimension to our mindfulness practice and provides us with tremendous spiritual and meditative energy. This causes the mind to expand and become much more generous, and we start to see that there exists no challenge or obstacle that is insurmountable.

This newly arisen focus and broadening of perspective relates very closely to the concept and practice of 'right intention' that forms part of the Noble Eightfold Path. Right intention basically means that with both ours and other's longterm benefit in mind, we set our intentions firmly on becoming enlightened. Due to seeing clearly that all phenomena are impermanent and that our time here is limited, we are willing to work hard in order to leave suffering behind. By practising mindfulness with a firm intention to actualize our potential for enlightenment, we tap into the lineage blessings that lie latent within each and every one of us.
The lineage we are referring to here is the universal Dharma lineage - or you can call it the lineage of mindfulness if you prefer. It belongs to nobody yet everybody can access it. It exists within every sentient being but only reveals itself to those that choose to live in awareness. In order to acquire this universal lineage, we do not need anybody's permission. We do not need to be empowered by another person and we do not need to attend any initiation ceremonies. We empower ourselves simply by being sincere and diligent in our practice. In fact, if you are sincere in your mindfulness practice-if your intentions are pure and wholesome - then progress and results will follow naturally. At this point, it doesn't matter in the slightest whether you belong to a religion or a meditation tradition, nor does it matter whether you have undergone an extensive study of the spiritual texts. You can take your place as an authentic heir to the mindfulness lineage. What's more and for what it is worth, although you don't need anybody's authorization to practice this lineage - as long you remain completely true and sincere in your practice-you have our full blessings and authorization to do so.

Along with being a holder of the lineage of mindfulness come a tremendous responsibility to keep the lineage teachings alive and authentic. However, the way to do this is not by trying to own or protect the lineage, but by letting go of it. This is because lineage is, and has to be, completely dynamic. As you grow in awareness, the teachings that are all around and within you change and present themselves in different ways. Therefore, if you want the lineage to endure and remain effective, then you have to allow it to evolveand you have to evolve with it. The way to allow things to evolve is to simply be and allow experience to unfold without clinging to it. You have to understand that the moment you become attached to the lineage of mindfulness, it slips through your fingers and you cease being an authentic lineage holder.

We would like to conclude this article with a four-verse vajragiti (a kind of spiritual song) that we wrote called 'Hearken to the Dharma'.

\section{Hearken to the Dharma}

All you 'great' teachers and meditators,

Who mistake self-grasping and pride for the two accumulations,

In whom true renunciation and devotion never arise,

You, pleasure seekers, hearken to the Dharma that keeps death in mind.

Proudly claiming to be great Buddhists, Judging others as 'right' and 'wrong', Spreading doubt and disparaging the Law Holders, You, Dharma destroyers, hearken to the Dharma beyond all concepts. 
Practicing sophistry you deceive the foolish, Competing for renown like Mara princes, Dragging your followers to the miserable realms, You, evil doers, hearken to the Dharma of karmic cause and effect.

For View you delight in 'self' and 'other', For Meditation you indulge in scheming thoughts,
For Action you mindlessly vomit through your three doors. You, delusion revellers, hearken to the Dharma that knows Mind as all.

Acknowledgments Some parts of this article are much expanded upon and/or adapted themes and contemplations that first appeared on the authors' meditation blog (www.edoshonin.com). 